\title{
A note on mans in Toronto*
}

\author{
Derek Denis \\ University of Victoria
}

This paper serves as a short note about an ongoing innovation in the pronominal system of multiethnic adolescent Toronto English. The plural noun mans is in the early stages of grammaticalizing into a first person singular pronoun in this speech community in a way similar to the development of man in Multicultural London English (Cheshire 2013). To illustrate the function and distribution of mans, examples are taken from a variety of data sources including reflexive performances of and meta-commentary about multiethnic adolescent Toronto English. While mans in Toronto English is similar to man in London, critical differences exist. The presence of such a similar innovation in both Toronto and London leads to several empirical questions about language contact, diffusion, group second language acquisition, and grammaticalization.

Pronominal systems are said to be "diachronically fairly stable" in contrast to other domains of language (Heine and Song 2011: 587). For example, if one takes into account regular sound change, the majority of Modern English pronouns can be straightforwardly traced to the reconstructed pronominal system of Proto-Indo-European with little appeal to reanalysis, analogy, borrowing, or any other kind of change (e.g., *'égh $>I$; *úswe $>u s,{ }^{*} y \hat{\mathrm{u}}>$ you). ${ }^{1}$ Given their cross-linguistically conservative nature, it is rather rare to observe the actuation of a new pronoun. As such, "not much progress has been made in unraveling the development of personal pronouns" (Heine and Song 2011: 587-8). However, Cheshire (2013) provides one such rare case study which traces the grammaticalization pathway of a new pronoun in the emerging variety of Multicultural London English (MLE). The emerging pronoun - man, used with primarily first person singular reference, as in (1) - is argued to have grammaticalized from a polysemous plural noun.

(1) Sue: were you popular then?

William: course yeah man is well known

(Cheshire 2013: 632)

This paper presents some preliminary findings with respect to a similar phenomenon in the English of the multiethnic adolescent Toronto speech community. The pronoun mans, which also primarily occurs with first person singular reference, as in (2), is emerging. ${ }^{2}$

(2) Yah, it's actually really good to be here dawg. You know like, I couldn't take the TTC but mans made it over anyway . so I'm excited dawg.

(Black Jeopardy, SNL sketch feat. Drake, 2016)

\footnotetext{
*Many thanks to Nastassia Guarda who first told me about this phenomenon in the Toronto context after discussion of Cheshire 2013 in Urban Dialectology, Winter 2015 at the University of Toronto. Many thanks to Alex Motut, Jacqueline Peters, Alex D'Arcy, Nicole Holliday, and Jenny Cheshire for discussion. Thanks also to TWPL editors Ruth Maddeaux and Clarissa Forbes for feedback. This work was supported by a SSHRC Postdoctoral Fellowship (2015-2017).

${ }^{1}$ Reconstructions from Ringe (2006: 57). One obvious exception is the set of third person plural pronouns which were borrowed from Old Norse.

${ }^{2}$ Following internet convention, I spell the address form dawg as such. TTC is the Toronto Transit Commission, Toronto's public transportation organization.
} 
The development of mans in Toronto shows similar properties to MLE's man but with critical differences with respect to the lexical source and ultimate morphological form. The parallel and unique development of these two forms provides further evidence for Cheshire's (2013) argument that MLE's pronominal man grammaticalized from a polysemous plural noun whose reference is contextually-defined; I argue that mans follows the same general path in Toronto.

The paper is organized as follows. In section 2, I introduce the data from MLE and summarize Cheshire's (2013) proposal about the development of man. Section 3 presents the mans data from Toronto, its sources, and its properties. Section 4 presents some hypotheses about the source of mans in Toronto. Lastly, in the final section I speculate that Toronto, like London, contains an emerging adolescent multiethnolect which to date has been un(der)studied.

\section{Man in Multicultural London English}

Multicultural London English is a multiethnolect (coined by Clyne 2000) - a variety "linked to specific types of community formation in urban areas which have seen very large-scale immigration from developing countries [with] people of different language backgrounds [...] settl[ing] in already quite underprivileged neighbourhoods" (Cheshire, Kerswill, Fox, and Torgersen 2011: 153). The epicentre of this speech community is in the multiethnic, multilingual working class neighbourhoods of the East End of inner-city London. MLE is colloquially considered a form of 'Black' English, sometimes referred to in the media as 'Jafaican' (Kerswill 2013: 160-1). While Jamaican English is evidently a lexical influence (Cheshire et al. 2011: 164), MLE is not simply a heritage variety. The multilingual and segregated nature of communities where MLE is spoken means that the majority of face-to-face exposure to English for the young (often British-born) children of recent immigrants who live in these neighbourhoods is their peers and siblings. The result is an environment with multiple linguistic influences: the ambient standard and nonstandard varieties, various varieties of outer-circle World Englishes and English-lexifier creoles spoken by recent immigrants from the West Indies, south Asia, and Africa, learner varieties of English, and potentially languages other than English (Kerswill 2013: 133). Among a variety of innovations (including a unique vowel space, a new quotative (this is + SPEAKER), and the simplification of definite and indefinite article allomorphy, see Cheshire et al. 2011), Cheshire (2013) observes the development of a new pronoun in MLE (and other inner city speech communities in England). The innovative pronoun man primarily functions with first person singular indexicality ( $\sim 70 \%$ of Cheshire's tokens), as in (3a), but can also refer to second persons, as in (3b), and third persons, both referential (3c) and as an indefinite (3d).

(3) a. I don't really mind how . how my girl looks if she looks decent yeah and there's one bit of her face that just looks mashed yeah. I don't care it's her personality man's looking at

(Cheshire 2013: 633)

b. man's trying to take me for some kind of idiot ("female addressing her errant boyfriend")

(Cheshire 2013: 615)

c. man's only known you for about five minutes and even he's onto you (Cheshire 2013: 615)

d. man's got to jump up to hit him he could just go bang bang and pushing fist start hitting youse and that's it $^{3}$

(Cheshire 2013: 633)

\footnotetext{
${ }^{3}$ Researchers of racialized and marginalized speech communities have a problematic habit of exemplifying linguistic features in the context of excerpts that involve reductionist (and frequently negative) stereotypes. In some cases, the speech of community members that do not fit the narrative of the 'authentic speaker' have even been ignored (see Holliday 2016: 80-1 for discussion; see also Morgan 2006, Coupland 2003). While I have tried to avoid using problematic examples, the paucity of tokens in my data and Cheshire's has made it necessary on occasion to include content that furthers negative, reductionist stereotypes. That said, it may be of discourse-analytic interest that man and mans occur in discourse that involves such content and thus may function as an index to a particular 'street'
} 
As with all of the examples in (3), the majority of pronominal man tokens in Cheshire's (2013) data are subjects (though there are some object/oblique and possessive tokens) and trigger third person singular verbal agreement.

Cheshire (2013) argues that the pronominal use of man grammaticalized from a polysemous plural noun man, as in (4a). Like Cheshire, I assume that pronouns are 'more grammatical' than nouns and thus a change from noun to pronoun is a case of grammaticalization - "the process whereby items become more grammatical through time" (Hopper \& Traugott 1993: 2). ${ }^{4}$

The reference of this plural noun is (situationally- or linguistically-)contextually-defined; in (4a) man occurs with the MLE quantifier bare 'many', and in (4b) and (4c) man co-occurs with you and them which deictically refer to contextually relevant individuals.

(4) a. and I ended up hanging around with bare bare man

(Cheshire 2013: 617)

b. you man are all batty boys though

(Cheshire 2013: 617)

c. them man will kill me

(Cheshire 2013: 617)

In MLE, other plural forms of man also exist including men, mens, mans, and mandem (with the Englishlexifier Creole plural marker) as in (5). However, the morphologically unmarked man is by far the most frequent form of the plural noun $(\sim 66 \%)$.

(5) a. I wanna be with the mandem innit your friends who you grew up with

b. $\quad$ if you put all the mans together make them fight a cause together

(Cheshire 2013: 616)

(Cheshire 2013: 616)

c. most Congolese mens in this country yeah they look funny cos like they got expensive clothes they wear all these Versace clothes D and G all that

(Cheshire 2013: 616)

In some cases, man is ambiguously a pronoun or this contextually-defined plural noun. In (6), man is either a determiner-less plural noun following the semantically equivalent people or is "a pronoun referring deictically to "us' or anaphorically to 'the people"' (Cheshire 2013: 617).

(6) he's rapping for the people he's rapping for man

(Cheshire 2013: 617)

Cheshire (2013: 619) argues that the grammaticalization of pronominal man was spurred by the high frequency of the polysemous plural noun man; this use of man to refer to a contextually-defined group "paves the way for the form to emerge as a pronoun whose reference is defined in an identical way". Pronominal man, as grammatically third person singular (it triggers third person singular agreement), has no deictic index (speaker nor addressee) in the same way that other third person pronouns do not. So, like third person pronouns, the denotation of $\operatorname{man}$ is always contextually determined. ${ }^{5}$ Thus, the grammaticalization is driven by the pragmatic extension of the lexical item man to being interpreted with first or second person indexicality and the semantic bleaching of the noun's plurality and to some extent its 'maleness', though

persona. Thanks to Nicole Holliday (p.c.) for her insight on this issue.

${ }^{4}$ Déchaine \& Wiltschko (2002) among others argue that pronouns are not a primitive category in language but rather at least three kinds of pronouns exist which are distinguished by their morphological status. I do not go into any detail about the structural properties of $\operatorname{man}(s)$ vis-à-vis other English pronouns or what the exact reanalysis that occurred from lexical noun to grammatical pronoun might have looked like. I leave these questions for future research.

${ }^{5}$ Collins and Postal (2012: 5) discuss the phenomenon of imposters - "a notionally X person DP that is grammatically Y person, $\mathrm{X} \neq \mathrm{Y}$ ", as in (i). Alex Motut (p.c.) points at that man(s) may have undergone a stage as an imposter (or perhaps is synchronically best analyzed as an imposter).

(i) a. This reviewer was unable to strictly follow the logic of the submission.

(Collins \& Postal 2012: 2)

b. Would the baroness like more wine?

(Collins \& Postal 2012: 2) 
Cheshire (2013: 624) notes the the majority of first person singular pronominal man tokens are spoken by male speakers. That the form of the pronoun is the same as the most frequent morphological realization of the plural noun is thus unsurprising; the plural noun is the lexical source of the pronoun.

This grammaticalization pathway is not unique (Cheshire 2013). Laberge \& Sankoff (1980: 272) note that in Montréal French on (ultimately from Latin home 'man') "has acquired the ability to substitute for any and all of the personal pronouns" in much the same way as man (and mans as I will show). Furthermore, Laberge \& Sankoff's (1980: 272) translation of (7) emphasizes the speaker's distancing himself from the discourse in a way similar to how Cheshire (2013) notes speakers of MLE use man.

(7) B: J'ai cassé le steering avec mon genou parce que j'étais assis de côté.

A: Et puis vous êtes correct?

B: Ah, oui, on s'en vient petit vieux, mais on est correct

B: 'I broke the steering wheel with my knee because I was sitting on the side.

A: And you're okay?

B: Oh yes, the old man's getting on, but he's all right.'

Among other examples, Heine \& Song (2011) also discuss the Thai first person singular form khâa (> 'servant'), the Brazilian Portuguese first person plural a gente ( $>$ 'the people'), and the Spanish second person formal usted ( $>$ and vuestra merced 'your grace/mercy'). Within the English context, Jones \& Hall (2015) have discussed the emergence of a first person singular pronoun a nigga (from the racial epithet) in some varieties of African American English. In all these cases, the pronominal form developed from a human denoting noun, similar to man in MLE.

\section{$3 \quad$ Mans in Toronto English}

Multicultural London English is not the only variety of English with an emerging pronoun ultimately from the noun man. For the remainder of this paper, I focus on a very similar phenomenon that has been underway in Toronto for approximately the last decade. In the multiethnic adolescent Toronto English speech community, mans functions as a pronoun, primarily with first person reference. In this section, I present several tokens of mans in Toronto English and discuss the properties of this form and the connection to the contextually-defined plural noun mans. Many parallels can be drawn between mans in Toronto and man in MLE but critical differences exist. The differences between these two innovations are derivable from the developmental trajectory that Cheshire (2013) proposes mutatis mutandis.

\subsection{Data}

To the best of my knowledge, the use of pronominal mans has not been recorded in the context of sociolinguistic interviews of Toronto English. Tagliamonte's (2006) Toronto English Archive, while vast in scope, was recorded between 2003 and 2004 - this is likely prior to the onset of mans in Toronto (see Section 4). My own small corpus of twenty-four interviews with 18 to 30 year old Torontonians recorded in the winter of 2015 contains no examples. However, this lack of tokens is not surprising. In Cheshire's (2013: 610) sociolinguistic interview data, which come from two projects consisting of approximately 2.8 million words (Cheshire et al. 2011: 157-8), only eleven unambiguous tokens of pronominal man from six speakers were recorded. Thus, to exemplify the use and function of mans in Toronto English I have turned to alternative sources. In total, I consider fifty-four mans tokens of which thirty-four are pronominal (or at least ambiguously pronominal); a few tokens of man dem and man are also discussed. Table 1 summarizes the sources of the data. 
Table 1: Summary of data sources: mans, man dem, and man.

\begin{tabular}{llcc}
\hline Type of media & Name & Year & Tokens (pronoun) \\
\hline YouTube video & Shit Toronto People Say & 2012 & $3(2)$ \\
YouTube video & Shit Toronto People Say: Gyal Dem Edition & 2012 & $3(1)$ \\
YouTube video & Toronto Parents in 2040 & 2015 & $2(2)$ \\
YouTube video & Toronto Parents in 2040, part 2 & 2015 & $2(2)$ \\
YouTube video & Toronto Slang 101 & 2016 & $1(1)$ \\
Saturday Night Live & Black Jeopardy sketch feat. Drake & 2016 & $1(1)$ \\
Music video & Jungle, Drake & 2015 & $1(1)$ \\
Song & R.I.C.O., Meek Mill feat. Drake & 2015 & $2(0)$ \\
Song & Keep The Family Close, Drake & 2016 & $1(1)$ \\
Song & Controlla, Drake & 2016 & $1(1)$ \\
Text/Instant messaging & - & 2015 & $3(2)$ \\
Twitter & publicly available \#TorontoSlang tweets & $2010-6$ & $39(23)$ \\
ToтAL & - & & $58(37)$ \\
\hline
\end{tabular}

Several of my tokens come from a set of YouTube videos, posted between 2012 and 2016, that focus on contemporary Toronto slang. Because my goal for this paper is to provide a description of the use of mans and to provide some hypotheses about its development, I sought out videos in which mans appears at least once. ${ }^{6}$ In other words, the number of tokens in these videos should not be taken as a general reflection of its frequency in Toronto. Four of the videos are produced by YouTube user ThatdudeMCFLY and take the form of short excerpts of young Torontonians in conversation that exemplify some feature of Toronto English. A fifth video from user COSMEHOLICS ANONYMOUS features a couple discussing the meaning of various Toronto slang words and phrases. Another set of tokens come from Toronto rapper and actor Drake. Not only is Drake Toronto's most popular and successful entertainer of the last decade, he frequently features references to the city in songs, album cover art, and music videos. Indeed, he is the most globally-visible and well-known representative of the multiethnic adolescent Toronto speech community. Tokens of mans from Drake include instances in song lyrics, music videos, and a 2016 Saturday Night Live sketch featuring Drake portraying a 'black Canadian'. The four tokens from Drake's lyrics represent the exhaustive tokens of mans in all his four albums, six mixtapes, and one EP (released between 2006 and 2016). Three more examples come from text/instant message conversations between young Torontonians. ${ }^{7}$ Finally, I consider 38 tokens from publicly available tweets that contain the hashtag \#TorontoSlang in which Twitter users share examples of stereotypes of vernacular adolescent Toronto English. ${ }^{8}$ Most of these \#TorontoSlang tweets take the form of an example utterance which contains Toronto slang words and expressions. Three of the tokens that contain mans are not example utterances but rather meta-linguistic commentary about the use of mans in Toronto. These tweets were accessed through the search function built into Twitter's web interface.

For the remainder of this section I discuss the properties of mans in Toronto and the properties of

\footnotetext{
${ }^{6}$ That said, of the six videos I considered in the genre of contemporary Toronto slang, five contained mans.

${ }^{7}$ Two of these examples were voluntarily shared with me and permission was given to discuss them here by the speakers. One token is from Dinkin's (2014) corpus of Toronto text messaging English. That token is the one token of mans in the $\sim 23000$ word corpus. Many thanks to Aaron Dinkin for searching this data set for mans and granting permission to include the example.

${ }^{8}$ The hashtag seems to have been in use since at least 2010 and on January 14, 2012 it was used so frequently that it trended worldwide. Thirty-three of the tokens I discuss are from the 763 \#TorontoSlang tweets posted from Jan. 15, 2012 to July 3, 2016. Two tokens are from prior to this and are used to establish a timeline.
} 
pronominal mans in relation to the plural noun mans. For analytical purposes, I focus on the tokens that come from sources other than \#TorontoSlang tweets because the reference of mans in the majority of these tweets is ambiguous as context is limited to 140 characters.

\subsection{Properties of mans in Toronto}

In (8) through (10), I present the thirteen tokens of pronominal mans in the non-Twitter sources. One token of pronominal man dem is also included. (8) contains the eight tokens with unambiguous first person, singular reference.

(8) Unambiguously first person, singular reference:

a. Yah, it's actually really good to be here dawg. You know like, I couldn't take the TTC but mans made it over anyway . so I'm excited dawg.

(Black Jeopardy, SNL Sketch, 2016)

b. mans are out and off of Facebook!; I'll talk to you later (Facebook message, 2015)

c. Anytime people want to start problems; It's like "for real, are you dumb?"; You know who mans are; I'm not afraid no gyal heart man. (Keep The Family Close outro, Drake, 2016)

d. But you can't just diss and come tell mans sorry; You can't listen to me talk and go tell my story.

(Controlla, Drake, 2016)

e. A: Yo that's why mans need a whip.

B: I'm sure- B, you need a whip?

(Shit Toronto People Say: Gyal Dem Edition, 2012)

f. Mans have it eh.

(Toronto Slang 101, 2016)

g. Yo what time is your parent-teacher interview thing? Mans might have to flop on that still.

(Toronto Parent in 2040, 2015)

h. Yo B listen- yo man dem either play next game or no one's playing bro.

(Shit Toronto People Say, 2012)

In the first four examples in (8), the alternation with $I$ (or me) indicates first person reference of mans. Linguistic context is similarly relevant for the interpretation of (8e); speaker A says mans need a whip and speaker B responds with an echo question replacing mans with you. In (8f), physical deixis is involved; in the video, the speaker holds a fist to his chest when he says mans. Explicit discussion of the meaning following the token confirms this. In the remaining examples, the situational context makes it clear that the reference is the speaker. The last example is the only unambiguously pronominal token in my data that is not mans. Rather, man dem is used with first person singular reference. While mans in the majority of these examples functions as a subject, in (8d) it is an object. While rare in comparison to being a subject, this is not an isolated token. In at least one of the \#TorontoSlang tweets, mans also functions as an object.

Next, consider the two examples with unambiguous second person singular reference. In both these examples, the speaker walks into a room and addresses a single individual.

(9) Second person singular reference:

a. Holy . fuck B . say mans dun know where the closet is eh? (Toronto Parents in 2040, 2015)

b. What are mans saying? (Toronto Parents in 2040, pt. 2, 2015)

The last four pronominal tokens are ambiguous between first person reference and indefinite/impersonal reference (cf. one, you, people) and the context does not clarify.

(10) Ambiguously indefinite/first person:

a. So yo say, mans can't get a discount then?

b. Yo dawg! Manz are waiting for that part 2 stillz

(Shit Toronto People Say, 2012)

(Toronto Parents in 2040 pt. 2, 2015) 
c. It's like mans are on road . it feels like anybody's a target, you know?

d. PK: Rebecca black is my sistaaaa

(Jungle [music video], Drake 2015)

P: damn son you better talk to her this ain't holy love shes feeling

PK: shes the greatest singer of life man

P: mans are dying good night

PK: goodnight loser : )

(Text message, Dinkin 2014)

While there is variation with respect to the reference of pronominal mans in Toronto, there is no variation in its agreement pattern; with present tense verbs, the inflection is always non-third-singular (and in the case of be, non-first-singular) both in the above examples and in the Twitter data. This is consistent with it being grammatically a third person plural (as man is MLE in grammatically third person singular).

In addition to pronominal mans, the data sources consulted also contain several examples of plural forms of the noun man that function to identify a contextually-salient group. Cheshire (2013) argues that the contextually-defined plural noun man serves a critical role in the grammaticalization of the pronominal use of man in MLE. As with MLE, there is morphological variation in the realization of the plural form of man in Toronto. All of the examples below are unambiguously nouns as they are modified by a determiner or adjective.

\section{(11) Nominals:}

a. $\quad$ They told me to tell you you mans are some waste mens.

(R.I.C.O., Meek Mill feat. Drake, 2015)

b. $\quad$ youre a junction kid; Softest mans out here

(Text message, 2015)

c. Every time I go there, bare mans are trying to hollar at me . but yo, who's begging?

(Shit Toronto People Say: Gyal Dem Edition, 2012)

d. Yo you can't disrespect the man dem?

(Shit Toronto People Say, 2012)

e. Two twos, I rode up on a whip, and the man wouldn't come out of the whip. I was like "yo is it a beef ting?" . like "what a gwan?"

(Shit Toronto People Say: Gyal Dem Edition, 2012)

The first three examples represent the frequent form mans. In (11a), we also see an example of mens in the context of the frequent collocation waste man ('a worthless person'). This is the only example of mens in the data. (11d) contains an example of man dem which is also frequent in the data. The final example shows the use of man as a singular noun whose reference is a contextually-salient individual. In contrast to MLE, man neither appears as a plural noun or a pronoun in the Toronto data. Indeed, none of the \#TorontoSlang tweets that also contain man $(\mathrm{n}=366)$ use man as an unambiguously plural noun or pronoun as Cheshire (2013) describes for MLE. This is an important observation with respect to the development of pronominal mans and will be explored further below.

To summarize, mans in Toronto can be used to reference the speaker and the addressee as well as potentially an indefinite third person pronoun. The form can also serve as subject or object/oblique. Regardless of reference, the verbal agreement indicates that the subject form is grammatically not third person singular nor first person singular (i.e., it does not trigger verbal $-s$ agreement and the form of to be in the present tense with subject mans is are). Furthermore, mans is one among several morphological realizations of a contextually-defined plural noun. With these properties in mind, we can now hypothesize about the source of mans in Toronto.

\section{$4 \quad$ The source of mans in Toronto}

The earliest mention of pronominal mans I have found on the internet is a 2006 post on Urban Dictionary which makes no reference to any regional or ethnolectal variety. The post is repeated in (12) verbatim. 
(12) Manz: Just a word that boys that think their hard use instead of refering to themselves as "I"; "Manz got arrested!"

(Urban Dictionary, May 26, 2006)

Cheshire's (2013) earliest tokens in MLE come from sociolinguistic corpora recorded between 2004 and 2010. The earliest tweet which uses the \#TorontoSlang hashtag and contains mans (or manz) comes from Dec. 26, 2010. Mans in this tweet, shown in (13), is ambiguous between a plural noun and a pronoun. The earliest unambiguous first person singular pronominal use of mans is from an August 11, 2011 tweet, shown in (14).

(13) \#torontoslang mans are parrow in the dot

(@annitanocitra, 26 Dec 2010)

(14) i just woke up from a nap.... HOLYYYY MANS ARE MARVEDDDDD BREDDDJIN! \#TorontoSlang

(@Kamakacci_Juice, 19 Aug 2011)

If we assume that the \#TorontoSlang hashtag is used by Twitter users to identify stereotypes of vernacular adolescent Toronto English, then by 2011, and likely by 2010, mans was associated with this speech community: from Sep. 30, 2010 to present 498 \#TorontoSlang tweets contain the word mans (though this includes both nominal and pronominal forms). Two of these tweets, in (15), which function as meta-linguistic commentary, explicitly suggest this association.

(15) a. I've been saying "mans" a lot lately. \#TorontoSlang is getting to me lol.

(@BenitaSinghs, 28 Mar 2016)

b. Is it me or do only the GTA highschoolers classify a group of males as mans "..LOL." \#torontoslang

(@DPrizzy, 19 Apr 2012)

The question now is, what is its source?

\subsection{Diffusion from London?}

One possible hypothesis for the source of mans in Toronto is from borrowing MLE's man. While it may well be possible for features of MLE to globally diffuse, and indeed an equally multicultural metropolis such as Toronto could be a possible adopting community, there is evidence to suggest that borrowing from MLE was not the source for mans in Toronto. Foremost, the forms in London and Toronto differ in their morphological form - man in London and mans in Toronto. While Labov (2007) suggests that diffusion usually results in imperfect replication, this seems to apply to more abstract properties of linguistic features; surface forms are easily diffused (see Tagliamonte \& Denis 2014; Denis \& Tagliamonte in prep.). It is possible that man was diffused from MLE to Toronto and a subsequent change took place in Toronto which resulted in mans, but in this scenario we would expect to see evidence that man was used more frequently in the earlier data followed by variation with and eventually change toward mans. This is not the case. In the \#TorontoSlang tweets prior to 2012, man is not used pronominally (or even ambiguously between a pronoun and noun); mans is the primary pronominal form (and competes robustly with man dem as the plural noun form) in Toronto across the whole range of the data. Furthermore, that the timeline for mans in Toronto and man in London overlap substantially suggests parallel, rather than serial developments.

\subsection{Parallel diffusion from Caribbean English-lexifier creoles?}

Toronto (along with London and New York) has one of the largest Caribbean communities outside the West Indies. In 2011, 627590 Canadians identified as ethnically Caribbean and among those 308425 
lived in the Greater Toronto Area (5.6\% of the region's population). ${ }^{9}$ This community is similar in size to London's Caribbean community. In 2011, of the 591016 Caribbean identified people in England and Wales, 344597 lived in London (7.1\% of the population). ${ }^{10}$ In both cities, Jamaica is the source of the majority of immigrants. Hinrichs (2014) contrasts the Jamaican diasporic communities in London and Toronto with respect to their maturity, labelling London as 'mature' and Toronto as 'emerging'. While it is the case that Jamaican migration began in earnest to London before Toronto (1950s versus mid-1960s), Toronto's Jamaican community is certainly mature in that it includes a large number of third(+)-generation Canadians. Indeed, a great deal of meta-linguistic commentary surrounding both Toronto and London English identifies the source of most features as being from West Indian Englishes and English-lexifier creoles, usually Jamaican Creole. In many cases, this is transparently true. For example, lexical items such as waste man (previously mentioned) and ting ('thing', 'object', 'event', 'woman') and the plural marker dem (e.g., man dem 'men', gyal dem 'girls'). Thus, another possible hypothesis is that mans in Toronto and man in MLE both diffused from the same source: Caribbean English-lexifier creoles.

Cheshire (2013: 614) points out that Jamaican Creole has a noun man meaning 'people' that in some contexts can also be interpreted as an impersonal pronoun directly akin to the German impersonal pronoun man 'you, one, people' which developed out of the noun Mann 'human male' and to the Old English man/mon which was replaced by one by the end of the fifteenth century (Los 2005). ${ }^{11}$ This ambiguity is exemplified in (16).

man kyaan bai bred

people/one can't buy bred

(Cheshire 2013: 614)

This feature is a possible source for the pronominal man and mans. Indeed, keeping with the theme of data that represents reflexive performance and meta-commentary, we have evidence that man was similarly used in Toronto English in the early 2000s. Toronto rapper Kardinal Offishall's 2001 song BaKardi Slang is an ode to Toronto-Caribbean English. While it does not contain any mention of mans, there is an example of man used to mean 'people' as it is used in Jamaican Creole (he himself is a child of Jamaican-born Canadians).

(17) You think we all Jamaican, when nuff man are Trini's; Bajans, Grenadians and a hole heap of Haitians; Guyanese and all of the West Indies combined; To make the T dot O dot, one of a kind.

(BaKardi Slang, Kardinal Offishall, 2001)

However, with respect to the source of pronominal man(s), the story is more complicated than straightforward diffusion from the West Indies: there does not seem to be a (non-impersonal) pronominal man $(s)$ in any Caribbean English-lexifier creoles. Thus, while it is possible that the Jamaican Creole generic noun man 'people' may have had some influence on the development of a contextually-defined plural noun man(s), the development of pronominal man in MLE and the development of pronominal mans in Toronto are home-

\footnotetext{
${ }^{9}$ National Household Survey Profile (99-004-X), May 8, 2013, Statistics Canada <http://www12.statcan.gc.ca/nhsenm/2011/dp-pd/prof/index.cfm>. Accessed July 11, 2016.

${ }^{10} 2011$ Census (Office for National Statistics), Ethnic group, local authorities in England and Wales, Table \# KS201EW. 11 December 2012. Accessed July 11, 2016.

${ }^{11}$ This seems to be relatively common in English-lexifier Creoles. Tok Pisin, a Pacific creole spoken throughout Papua New Guinea seems to have a similar generic noun man meaning 'people':
}

(i) Igat planti man bai igo EXPL many people FUTURE PRED.go 'There are lots of people who'll go' (Sankoff 1980: 84) 
grown, and seemingly independent, phenomena.

\subsection{Grammaticalization and the feature pool (in group second language acquisition)?}

If man and mans are indeed independent developments, we can ask why their forms are similar but differ in the two communities. Cheshire (2013: 625-6) appeals to grammaticalization and argues that the frequency of polysemous forms of man (especially as a plural noun, but also as an address form and a pragmatic marker) served to incubate "further grammatical function [i.e., pronominal usage], perhaps especially since the grammatical function of a pronoun has much in common with that of a noun". In other words, the pronominal use of man is a further grammaticalization of the most frequent morphological realization of the contextually-defined plural noun: man. Critically, man is the most frequent morphological realization, among a variety of different plural forms. If we apply similar logic to the situation in Toronto, it becomes clear why mans and not man is the pronominal form. Like MLE, there are a variety of plural forms of man in Toronto including men, mens, man dem, and mans. However, plural noun man does not appear in any of my source material. Rather mans is frequent and mans developed a pronominal function. Note also that man $d e m$ is a frequent realization of the plural noun and an early token of man dem (from 2012) is unambiguously pronominal. This suggests that these two forms were both available for pronominal development earlier in Toronto. It seems that today they have subsequently formed a complementary relationship (they developed paradigmacity in Lehmann's [1995: 132] sense) with mans as pronominal and man dem as the plural noun. A more recent \#TorontoSlang tweet, (18), suggests this complementarity.

$$
\text { Mans = one guy Man dem = one guy \#TorontoSlang ( @ getoutthebox, 15 Dec 2014) }
$$

In sum, the pathway from a plural noun which indexes a contextually-defined group to a pronoun that Cheshire (2013) argues for is the same in both communities, but the ultimate form differs; the contrast between MLE and Toronto arises from two speech communities each coming to consensus on different forms available in the 'feature pool' (Mufwene 2001; Cheshire et al. 2011). These parallel developments are summarized in Tables 2 and 3.

Table 2: Grammaticalization pathway for mans in Toronto

\begin{tabular}{lllll}
\hline Function: & $\begin{array}{l}\text { nominal } \\
\text { 'human male' }\end{array}$ & $>\begin{array}{l}\text { nominal } \\
\text { 'contextually-defined } \\
\text { (group of) male(s)' }\end{array}$ & $>\begin{array}{l}\text { pronominal } \\
\text { first person }\end{array}$ \\
\hline Form(s) & man $_{\mathrm{SG}}$, men $_{\mathrm{PL}}$ & $>$ & mans, man dem, man & mans \\
\hline
\end{tabular}

Table 3: Grammaticalization pathway for man in London

\begin{tabular}{lllll}
\hline Function: & $\begin{array}{l}\text { nominal } \\
\text { 'human male' }\end{array}$ & $>\begin{array}{l}\text { nominal } \\
\text { 'contextually-defined } \\
\text { (group of) male(s)' }\end{array}$ & $>\begin{array}{l}\text { pronominal } \\
\text { first person }\end{array}$ \\
\hline Form(s) & man $_{\mathrm{SG}}$, men $_{\mathrm{PL}}$ & $>$ man, mans, mandem, men, mens & $>$ man \\
\hline
\end{tabular}

The variety of pluralized forms of man available in Toronto and London is a result of their similar diverse, multicultural, and multilingual composition: some forms come from the ambient variety (e.g., men), some from the Englishes of immigrant speech community members (e.g., man potentially from Jamaican Creole and man dem from the Caribbean more generally), and some the result of an 'imperfect' learning that 
characterizes the kind of group second language acquisition (Winford 2003: 235) or shift-induced interference (Thomason and Kaufman 1988: 75) that Cheshire et al. (2011) argue can occur in the multicultural, multilingual milieux of London and indeed Toronto (e.g., mans and mens).

\section{$5 \quad$ Prospectus: A Multicultural Toronto English?}

Given the similarities between London and Toronto with respect to the extent of immigration, immigration patterns, multiculturalism, and multilingualism, it is reasonable to wonder whether a Multicultural Toronto English exists in the same way that Multicultural London English does. I am not the first to raise this question. Hoffman and Walker (2010 inter alia) have investigated several ethnic communities in Toronto in search of distinctive ethnolectal features though in most cases the results suggest quantitative rather than qualitative differences from the Anglo baseline speech community. Hinrichs (2014) explicitly discusses the possibility of a Multicultural Toronto English that is structurally influenced by Jamaican Creole in a similar way as MLE. Hinrichs (2014: 190), investigating the speech of four Jamaican-Canadians, ultimately claims that "[t]here is no evidence that such a new dialect is emerging in Toronto". However, his sociophonetic analysis of three vowels (FACE, TRAP and MOUTH/COW) come from relatively few speakers - four three of whom are 35 years old or older, and are thus not an ideal group to compare with Cheshire et al.'s (2011) adolescents. In contrast, Baxter \& Peters (2011) trace the constraints on $t / d$-deletion in Toronto's Black speech community to Jamaican Creole (as opposed to African American English or Anglo-Canadian English). Furthermore, Baxter \& Peters' (2011) participants were not limited to those with Jamaican heritage but included speakers of Somali and other West Indian heritage. Their results thus suggest a distinct, multicultural Black Toronto variety with influence from Jamaican Creole. Consonant with Baxter \& Peters (2011), pronominal mans is not restricted by ethnicity. In fact, it is neither ethnically- nor racially-restricted: tokens come from speakers who identify as Jamaican, East African, south Asian, European, and Canadian. Drake identifies as mixed; his father is African American and his mother is Jewish Canadian. Mans in Toronto is thus furthermore similar to man in London in its multiethnic profile.

While Hinrichs (2014) suggests that a multiethnic variety does not exist in Toronto, I contend that linguists (perhaps with the exception of Baxter \& Peters 2011) have yet to be in any position to observe it. Consider Cheshire and colleagues' data: to investigate MLE required interviewing adolescents and children as young as 4 , in dyads or small groups with interviews conducted by a young, British-Asian male. It is unlikely that features such as mans would appear in a traditional one-on-one sociolinguistic interview conducted by anyone too far removed from the community, and certainly not with an older age cohort considering its novelty. And yet, the \#TorontoSlang hashtag and videos such as Shit Toronto People Say suggest that something new is indeed emerging. Beyond mans (and potentially a $t / d$-deletion process like that of Jamaican Creole), other speculative features of an adolescent Multicultural Toronto English include th-stopping (though this is a vernacular universal), monophthongization of diphthongs (but especially [ow] e.g., Are you j[o:]king?), non-participation in GOOSE-fronting and GOAT-fronting, extensive borrowings from Caribbean English-lexifier Creoles (e.g., cyattie, waste man, ting, and the response particle ahlie), borrowings from (Somali) Arabic (wallahi), and other home-grown features (address term fam, confirmational eh, utterance final concessive marker still/styll, and lexical innovations like lit 'amazing', cheesed 'pissed off' and to cut 'to leave') among others. ${ }^{12}$ While certainly some of these may be features of a transitory adolescent speech community, others may persist and come to define a new variety. Whatever the contemporary nature of these features, it is clear that they exist today and enregister an un(der)studied variety of multiethnic adolescent Toronto English.

\footnotetext{
${ }^{12}$ Some of these features are indeed shared with MLE but other well-attested features of MLE are not present in Toronto including the reduced negative polarity tag innit and the this is+SPEAKER quotative.
} 


\section{References}

Baxter, L., \& Peters, J. (2011). Black English in Toronto: A new dialect? Paper presented at Methods in Dialectology 14. August 2-6, 2011. University of Western Ontario, London, ON. Retrieved from http://www.academia.edu/2966441/Black_English_in_Toronto_A_New_Dialect.

Cheshire, J. (2013). Grammaticalisation in social context: The emergence of a new English pronoun. Journal of Sociolinguistics, 17(5), 608-633.

Cheshire, J., Kerswill, P., Fox, S., \& Torgersen, E. (2000). Contact, the feature pool and the speech community. Journal of Sociolinguistics, 15, 151-198.

Clyne, M. (2000). Lingua franca and ethnolects in Europe and beyond. Sociolinguistica, 14, 83-89.

Collins, C., \& Postal, P. M. (2001). Imposters: A study of pronominal agreement. Cambridge: MIT Press.

Coupland, N. (2003). Sociolinguistic authenticities. Journal of Sociolinguistics, 7(3), 417-431.

Déchaine, R.-M., \& Wiltschko, M. (2002). Decomposing pronouns. Linguistic Inquiry, 33(3), 409-442.

Denis, D., \& Tagliamonte, S. A. (2017). Language change and fiction. In M. A. Locher \& A. H. Jucker (Eds.), Pragmatics of fiction (to appear). Berlin: De Gruyter Mouton.

Dinkin, A. (2014). A phonological variable in a textual medium: (ing) in online chat. Paper presented at CVC8, Queen's University, Kingston, Ontario, June 1, 2014.

Heine, B., \& Song, K.-A. (2011). On the grammaticalization of personal pronouns. Journal of Linguistics, 47(3), 587-630.

Hinrichs, L. (2014). Diasporic mixing of World Englishes: the case of Jamaican Creole in Toronto. In E. Green \& C. Meyer (Eds.), The variability of current World Englishes (pp. 169-194). Berlin: De Gruyter.

Hoffman, M. F., \& Walker, J. A. (2010). Ethnolects and the city: Ethnic orientation and linguistic variation in Toronto English. Language Variation and Change, 22(1), 37-67.

Holliday, N. (2016). Intonational variation, linguistic style, and the Black/Biracial experience. New York University Doctoral dissertation.

Hopper, P., \& Traugott, E. C. (2003). Grammaticalization, second edition. Cambridge: Cambridge University Press.

Jones, T., \& Hall, C. (2015). Semantic bleaching and the emergence of new pronouns in AAVE. Paper presented at LSA Annual Meeting, Portland, January 8-11, 2015.

Kerswill, P. (2013). Identity, ethnicity and place: The construction of youth language in London. In P. Auer, M. Hilpert, A. Stukenbrock, \& B. Szmrecsanyi (Eds.), Space in language and linguistics: Geographical, interactional, and cognitive perspectives (pp. 128-164). Berlin: De Gruyter.

Labov, W. (2007). Transmission and diffusion. Language, 83(2), 344-387.

Lehmann, C. (1995). Thoughts on grammaticalization. München/Newcastle: Lincom Europa.

Los, B. (2005). The rise of the to-infinitive. Oxford: Oxford University Press.

Morgan, M. (2006). "I'm every woman": Black women's (dis)placement in women's language study. In M. Bucholtz (Ed.), Language and woman's place: Text and commentaries (pp. 252-259). Oxford: Oxford University Press.

Mufwene, S. S. (2001). The ecology of language evolution. Cambridge: Cambridge University Press.

Ringe, D. (2001). A linguistic history of English: Volume I. From Proto-Indo-European to Proto-Germanic. Oxford: Oxford University Press.

Tagliamonte, S. A. (2006). "So cool, right?": Canadian English entering the 21st century. Canadian Journal of Linguistics, 51(2/3), 309-331.

Tagliamonte, S. A., \& Denis, D. (2014). Expanding the transmission/diffusion dichotomy: Evidence from Canada. Language, 90(1), 90-136.

Thomason, S. G., \& Kaufman, T. (1988). Language contact, creolization and genetic linguistics. Berkley: University of California Press. 
Winford, D. (2003). An introduction to contact linguistics. Oxford: Blackwell.

\section{Sources}

[COSMEHOLICS ANONYMOUS]. (26 May 2016). TORONTO SLANG 101. [YouTube video file]. Retrieved from https://www.youtube.com/watch?v=RS9B1VcWAPQ

[ThatdudeMCFLY]. (19 Jan 2012). Shit Toronto People Say. [YouTube video file]. Retrieved from https:// www.youtube.com/watch?v=-Fi-rofkEv0

[ThatdudeMCFLY]. (27 Jan 2012). Shit Toronto People Say: Gyal Dem Edition. [YouTube video file]. Retrieved from https://www.youtube.com/watch?v=SBv3SNkI9sw

[ThatdudeMCFLY]. (20 May 2015). TORONTO PARENTS IN 2040!. [YouTube video file]. Retrieved from https://www.youtube.com/watch?v=DmHEME3NfJ0

[ThatdudeMCFLY]. (6 Jun 2015). TORONTO PARENTS IN 2040 PT. 2. [YouTube video file]. Retrieved from https://www.youtube.com/watch?v=O0qBOkpCeDI

Graham, A., Samuels, M., Ritter, A., Chin-Quee, D., McGregor, S., Davis, M., Dennis, D., Jackson, G., Roberts, P. \& Thomas, A. (2016). Controlla [Recorded by Drake]. On Views. New Orleans, Miami, and New York: Young Money Entertainment, Cash Money Records Republic Records.

Graham, A. \& Bidaye, M. (2016). Keep The Family Close [Recorded by Drake]. On Views. New Orleans, Miami, and New York: Young Money Entertainment, Cash Money Records Republic Records.

Harrow, J. \& Pitt, S. (2001). BaKardi Slang [Recorded by Kardinal Offishall]. On Quest for Fire: Firestarter Vol. 1. Santa Monica, CA: MCA Records.

Klein, R \& Tucker, B. (Head writers), \& King, D. R. (Director). (14 May, 2016). Drake. [Television series episode]. In L. Michaels (Executive producer), Saturday Night Live. New York: NBC Studios.

[October's Very Own]. (12 Feb 2015). DRAKE JUNGLE. [Vimeo video file]. Retrieved from https://vimeo.com/119416353

Williams, R., Graham, A., Hernandez, A., Ritter, A. Gomringer, K. \& Gomringer, T. (2015). [Recorded by Meek Mill featuring Drake]. On Dreams Worth More Than Money. Miami and New York: Maybach Music Group and Atlantic Records. 